\title{
Nutraceuticals: Nutritionally Functional Foods - an Overview
}

\author{
Nawsheen Bee Torabally ${ }^{1}$ and Hananeh Abdolrahman Rahmanpoor*1,2 \\ ${ }^{1}$ College of Pharmacy, Ajman University, Ajman, UAE \\ ${ }^{2}$ Al Riyadh Pharmacy, Sharjah, UAE
}

*Corresponding author: Hananeh Abdolrahman Rahmanpoor, College of Pharmacy, Ajman University, PO Box 346, Ajman, UAE

\section{ARTICLE INFO}

Received: 慧 February 23, 2019

Published: 蔧 March 07, 2019

Citation: Nawsheen Bee T, Hananeh Abdolrahman R. Nutraceuticals: $\mathrm{Nu}-$ tritionally Functional Foods - an Overview. Biomed J Sci \& Tech Res 15(4)2019. BJSTR. MS.ID.002728.

\begin{abstract}
Nutraceuticals have received considerable interest because of safety and substantial nutritional and therapeutic effects. Nutraceuticals used in the treatment and prevention of different diseases. Nutrients, herbals and dietary supplements are major components of nutraceuticals for maintaining of health, act against various disease conditions and thus promote the quality of life.
\end{abstract}

Keywords: Nutraceuticals; Functional foods; Nutrient; Diseases and Treatments; Medicine

\section{Introduction}

The term Nutraceuticals was derived from 'Nutrition' (a nourishing food or food component) and 'Pharmaceuticals' (a medical drug). "Nutraceutical" is a term coined by Dr. Stephen De Felice in 1989 , founder and chairman of the Foundation for Innovation in Medicine (FIM) [1,2]. Nutraceutical defined as - according to Dr. Stephen De Felice - a "food, or parts of a food, that provide medical or health benefits including the prevention and treatment of disease" $[3,4]$. Nutraceuticals range from isolated nutrients, dietary supplements, and specific diets to genetically engineered "designer" food, herbal products, and processed foods such as cereals, soups, and beverages [5]. Nutraceuticals are continuously developed and have quickly spread worldwide [6]. The global nutraceutical market is, according to the recent BCC research analysis, expanding at a compound annual growth rate (CAGR) of 7.5\%, would reach US \$285.0 billion by 2021 from US $\$ 198.7$ billion in 2016 [7-10].

\section{Benefits of Nutraceuticals}

Nutraceuticals may offer many benefits:

a) May increase the health value of our diet.

b) May help us live longer.

c) May help us to avoid particular medical conditions.

d) May have a psychological benefit from doing something for one self. e) May be perceived to be more "natural" than traditional medicine and less likely to produce unpleasant side effects.

f) May present food for populations with special needs (e.g. nutrient-dense foods for the elderly).

g) May easily be available and economically affordable [11].

The nutraceutical products are recognized and produce health benefits such as to reduce the risk of cancer and heart disease and also to prevent or treat hypertension, high cholesterol, excessive weight, osteoporosis, diabetes, arthritis, digestive upsets and constipation, not to mention headaches [12-14]. Nutraceuticals are available in concentrated forms as pills, capsules, powders and tinctures either as a single substance or as combination preparations.

\section{Nutraceutical Categories}

Nutraceutical is a broad term. There are many types of products that fall under the category of nutraceuticals [15]:

\section{Dietary Supplement Including}

a. Nutrients such as vitamins, minerals, amino acids and fatty acids and antioxidants.

b. Herbals: Herbs or botanical products as concentrates and extracts. 
c. Phytochemicals are polyphenols, isoflavonoids, anthocyanidins, phytoestrogens, terpenoids, carotenoids, limonoids, phytosterols, glucosinolates, and polysaccharides.

d. Probiotics are live microbial feed supplement for improving its intestinal microbial balance. Lactobacillus bacteria and bifidobacteria are most important and probiotics.

e. Prebiotics: A fermented dietary ingredient that allows specific changes both in the composition and/or the activity of the gastrointestinal microbiota that exchange benefits upon the host wellbeing and health.

\section{f. Nutraceutical Enzymes.}

g. Dietary Fibers includes non-starchy polysaccharides such as cellulose, hemicelluloses, gum and pectin, lignin and resistant dextrins.

\section{Functional Food/ Fortified Nutraceutical}

It constitutes fortified food from added nutrients or ingredients. For examples- Milk enriched with Vit. D, Orange juice fortified with calcium, Cereals flour added with fiber and folic acid.

\section{Farmaceuticals/ Recombinant Nutraceuticals}

Farmaceuticals is made of two words Farm and Pharmaceuticals. Medically valuable compounds from modified agricultural crops. Uses biotechnological methods usually.

\section{Medicinal Food}

The medicinal foods are formulated to be consumed under the supervision of a physician, and which are designed for the specific dietary management of a specific disease or conditions for distinctive nutritional requirements, and are established by the medical evaluation.

\section{Negative Sides of Nutraceuticals}

Nutraceuticals are used to accomplish desirable therapeutic outcomes with reduced side effects, has met with great monetary success. Health claims on nutraceuticals will alert the consumers as a part of an overall healthy diet and reduce the risk of certain diseases. Academic, scientific and regulatory organizations will consider ways to establish the scientific basis to support claims for the functional components of nutraceuticals. For nutraceutical industries, two challenges are faced; regulatory credibility and uncertain claims in labelling. The lack of quality control is an area of concern for nutraceuticals. Absence of quality control will increase the risk to the consumer and also results in a total lack of driving force to conduct an adequate research that shows the potential benefits of nutraceuticals or ensures their safety. The safety of nutraceuticals must be assured, and all the claims must be substantiated, truthful and non-misleading. Clinical research on specific nutraceutical products would help substantiate the potential medical or health values of these products. As a result, patients and health care professionals would know the facts about the benefit and the safety of the products being taken [16-18].

\section{Conclusion}

Nutraceuticals has shown their health benefits and disease prevention capability, which should be taken according to their acceptable recommended intake. Nutraceuticals can provide substantial health benefits especially in the prevention and/or treatment of acute and chronic human diseases, thereby promoting optimal health, longevity and quality of life. But its development depends on its quality, safety, long-term adverse effects, and toxicity as well as supplementation studies and clinical trials in humans. Development of better characterized and research proven products will help enhance consumer confidence in nutraceutical products in the world.

\section{References}

1. De Felice SL (1995) The nutraceutical revolution, its impact on food industry. Trends in Food Sci and Tech 6(2): 59-61.

2. Mannion M (1998) Nutraceutical revolution continues at Foundation for Innovation in Medicine Conference. Am J Nat Med 5: 30-33.

3. Sarin R (2012) Nutraceuticals: A review. International research Journal of pharmacy 3(4): 95-99.

4. Kalra EK (2003) Nutraceutical-Definition and Introduction. AAPS Pharm Sci 5(3): 25.

5. Biesalski HK (2007) Nutraceuticals: the link between nutrition and medicine. In: Kramer K, Hoppe PP, Wildman REC. Nutraceuticals and Functional Foods. In: Wildman Handbook of Nutraceuticals and Functional Foods ( $1^{\text {st }}$ edn). CRC Press, Newyork, USA, p. 1-9.

6. Childs NM (1999) Nutraceutical industry trends. J Nut Fun Med Foods 2(1): 73-85

7. Golla U (2018) Emergence of nutraceuticals as the alternative medications for pharmaceuticals. Int J Complement Alt Med 11(3): 155158.

8. Brower B (1998) Nutraceuticals: Poised for a healthy slice of the market. Nat Biotechnol 16(8): 728-731.

9. https://www.bccresearch.com/market-research/food-and-beverage/ nutraceuticals-markets-report-fod013f.html

10. De Felice SL (1992) Nutraceuticals: Opportunities in an Emerging Market. Scrip Mag.

11. Pandey M, Verma RK, Shubhini A Saraf (2010) Nutraceuticals: New era of medicine and health. Asian Journal of Pharmaceutical and Clinical Research 3(1): 11-15

12. Rajasekaran, G Sivagnanam, Rathinam Xavier (2008) Nutraceuticals as Therapeutic Agents-Review. Research J Pharm and Tech 1(4).

13. Packer L (2001) Nutraceuticals in health and disease prevention. Marcel Dekker Inc, New York, USA, p. 1-26.

14. Maddi VS, Aragade PD, Digge VG, Nitaliker MN (2007) Importance of nutraceuticals in health management. Pharmacognosy Rev 1:377-379.

15. Dureja H, Kaushik D, Kumar V (2003) Developments in nutraceuticals Ind J Pharmacol 35: 363-372.

16. Bagchi D, Preuss HG, Kehrer JP (2014) Nutraceutical and functional food industries: aspects on safety and regulatory requirements. Toxicol Letters 150: 1-2.

17. Zeisel SH (1999) Regulation of "Nutraceuticals". Science 285(5435) 1853-1855.

18. Gupta RC (2016) Nutraceuticals: Efficacy, Safety and Toxicity. Academic Press, Boston, MA, USA 
ISSN: 2574-1241

DOI: $10.26717 /$ BJSTR.2019.15.002728

Hananeh Abdolrahman R. Biomed J Sci \& Tech Res

(c) (i) This work is licensed under Creative

Submission Link: https://biomedres.us/submit-manuscript.php

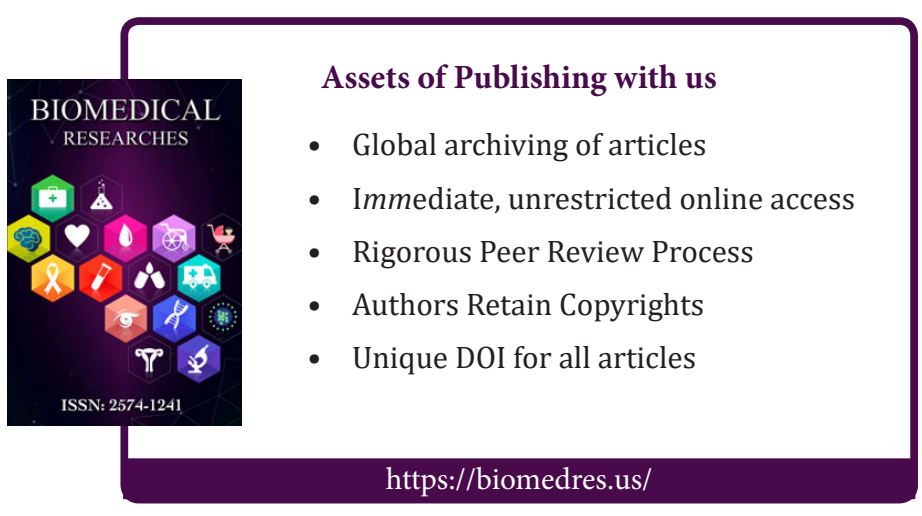

